\title{
Applying PROMETHEE Method based on Entropy Weight for Supplier Selection
}

\author{
Hossein Safari (Corresponding Author) \\ Assistant Professor, Faculty of Management, University of Tehran, Iran \\ E-mail: hsafari@ut.ac.ir \\ Maryam Sadat Fagheyi \\ M.S. Candidate of Industrial Management, University of Tehran, Iran \\ Email: m.faghei_66@yahoo.com \\ Saadeh Sadat Ahangari \\ M.S. Candidate of Industrial Management, University of Tehran, Iran \\ Email: s.ahangary@ut.ac.ir \\ Mohammad Reza Fathi \\ M.S. Candidate of Industrial Management, University of Tehran, Iran \\ E-mail: reza.fathi@ut.ac.ir
}

Received: April 17, 2012 Accepted: May 10, 2012 Published: June 1, 2012

doi:10.5296/bms.v3i1.1656 URL: http://dx.doi.org/10.5296/bms.v3i1.1656

\begin{abstract}
The aim of this study is applying a new integrated method for supplier selection. In this paper, the weights of each criterion are calculated using of Shannon's Entropy. After that, PROMETHEE is utilized to rank the alternatives. Then we select the best supplier based on these results. The outcome of this research is ranking and selecting supplier with the help of Shannon's Entropy and PROMETHEE techniques. This paper offers a new integrated method for supplier selection.
\end{abstract}

Keywords: Entropy, PROMETHEE, Supplier Selection 


\section{Introduction}

Supplier selection process has gained importance recently, since the cost of raw materials and component parts constitute the main cost of a product and most of the firms have to spend considerable amount of their revenues on purchasing. Supplier selection is one of the most important decision making problems including both qualitative and quantitative factors to identify suppliers with the highest potential for meeting a firm's needs consistently and at an acceptable cost. Jiang, Zhuang, and Lin (2006) evince the considerable impact of supplier selection and integration on customer satisfaction and business performance. With the development of information systems, it is becoming an important issue for SCM frameworks and applications to be capable of making decisions on their own ([Shemshadi et al., 2008] and [Soroor et al., 2009]), and it is not attainable until a well devised decision making process is deployed by an adequately improved software architecture. Supplier selection is a multi-criteria problem which includes both qualitative and quantitative factors. In order to select the best suppliers it is necessary to make a tradeoff between these tangible and intangible factors some of which may conflict (Ghodsypour \& O'Brien, 1998). The objective of supplier selection is to identify suppliers with the highest potential for meeting a firm's needs consistently and at an acceptable cost. Selection is a broad comparison of suppliers using a common set of criteria and measures. However, the level of detail used for examining potential suppliers may vary depending on a firm's needs. During recent years supply chain management and supplier selection process have received considerable attention in the literature. Supplier selection is a multi-criteria problem and there are not a lot of efficient techniques or algorithms that address this problem. However three major groups of methods in the literature are mathematical programming models cost based models, and categorical models. Since supplier selection problems usually have several objectives such as maximization of quality or maximization of profit or minimization of cost, the problem can be modeled using mathematical programming. Weber and Current (1993) proposed a multi-objective approach to supplier selection to aim at minimizing the price, maximizing the quality and on time delivery using systems' constraints and policy constraints in a mixed integer model. Ghodsypour and O'Brien (1998) proposed an integration of AHP and linear programming to consider both tangible and intangible factors in choosing the best suppliers and placing the optimum order quantities among them such that the total value of purchasing becomes maximum. Çebi and Bayraktar (2003) structure the supplier selection problem as an integrated lexicographic goal programming and AHP model including both quantitative and qualitative conflicting factors. Wang, Huang, and Dismkes (2004) use AHP and preemptive goal programming based multi-criteria decision-making methodology is then developed to take into account both qualitative and quantitative factors in supplier selection. Wang and Yang (2009) search supplier selection in a quantity discount environment using multi objective linear programming, AHP, and fuzzy compromise programming. Since price has traditionally been a leading factor, selecting suppliers based on cost has been a common approach. A popular application of the cost approach has been calculating the total cost for each purchase. The total cost of working with each supplier is calculated and the cheapest one is selected. Timmerman (1986) proposes cost-ratio method which collects all costs related to quality, delivery, and services and shows them as a benefit or penalty percentage on unit price. 


\section{Macrothink}

Ellram (1990) explains that a formal total cost approach explicitly recognizes cost factors in addition to price and argues that any total cost approach should include transportation costs, receiving costs, quality costs, purchasing administrative expenses and the price of the item. This paper is organized as follows. Section 3 presents the methodology. The application of the proposed method is addressed in Section 3. Finally, conclusions are provided in Section 4.

\section{Research Methodology}

In this paper, the weights of each criterion are calculated using Shannon's Entropy. After that, PROMETHEE is utilized to rank the alternatives. Finally, we rank the suppliers based on these results.

\subsection{Shannon's Entropy}

Entropy algorithm is a useful tool to acquire weights of criteria. Consider $\mathrm{P}_{\mathrm{ij}}$ in decision matrix for alternatives' evaluation. There are $\mathrm{n}$ alternatives and $\mathrm{K}$ criteria in decision matrix. The element of this matrix for jth criterion is as below:

$$
P_{i j}=\frac{f_{j}\left(a_{i}\right)}{\sum_{i=1}^{n} f_{j}\left(a_{i}\right)} ; \quad j=1,2, \ldots k \quad \forall j
$$

Entropy is calculated as below:

$$
E_{j}=-M \sum_{i=1}^{n} P_{i j} \ln P_{i j} ; \quad \forall j
$$

$\mathrm{M}$ is calculated as a constant value in next step:

$$
M=\frac{1}{\ln (n)}
$$

$\mathrm{E}_{\mathrm{j}}$ is a value between 0 and 1.

Next step is to calculate deviation degree $\left(\mathrm{d}_{\mathrm{i}}\right)$ which shows that to what extent jth criterion has useful information for decision maker. If there is little difference between one criterion values, it means that alternatives are indifferent according to this criterion so its effect in decision making should be diminished. Deviation degree is calculated as below:

$$
d_{i}=1-E_{i} ; \quad \forall j
$$

The final step in shanon entropy is to obtain weights based on following equation:

$$
w_{j}=\frac{d_{j}}{\sum_{j=1}^{k} d_{j}} ; \quad \forall j
$$




\subsection{The PROMETHEE Method}

The PROMETHEE (Preference Ranking Organization METHod for Enrichment Evaluation) is a multi-criteria decision- making method developed by Brans et al. (Brans and Vincke 1985; Brans et al. 1986). It is a quite simple ranking method in conception and application compared with other methods used for multi-criteria analysis. It is well adapted to problems where a finite number of alternatives are to be ranked according to several, sometimes conflicting criteria (Albadvi et al. 2007). The evaluation table is the starting point of the PROMETHEE method. In this table, the alternatives are evaluated on the different criteria. The implementation of PROMETHEE requires two additional types of information, namely: (1) Information on the relative importance that is the weights of the criteria considered.

(2) Information on the decision-maker's preference function, which he/she uses when comparing the contribution of the alternatives in terms of each separate criterion. The weights coefficients can be determined according to various methods (Nijkamp et al. 1990; Mergias et al. 2007). Shannon method is used to determine the criteria weights in this study. The PROMETHEE method is appropriate to treat the multi-criteria problem of the following type:

$\max \left\{f_{1}(\mathrm{a}), f_{2}(\mathrm{a}), \ldots, f_{\mathrm{n}}(\mathrm{a}) \mid \mathrm{a} \in \mathrm{A}\right\}$,

where $\mathrm{A}$ is a finite set of possible alternatives, and $f_{j}$ denotes $\mathrm{n}$ criteria to be maximized. For each alternative, $f_{j}(a)$ is an evaluation of this alternative. When we compare two alternatives $a, b \in \mathrm{A}$, we must be able to express the result of these comparisons in terms of preference. We, therefore, consider a preference function $P$. The preference function translates the difference between the evaluations of two alternatives ( $a$ and $b$ ) in terms of a particular criterion, into a preference degree ranging from 0 to 1 . Let

$$
\begin{aligned}
& P_{j(a, b)}=G_{j}\left[f_{j}(a)-f_{j}(b)\right], \\
& 0 \leq P_{j(a, b)} \leq 1,
\end{aligned}
$$

be the preference function associated to the criterion, $f_{j}(i)$ where $G_{j}$ is a non-decreasing function of the observed deviation $(d)$ between $f_{j}(a)$ and $f_{j}(b)$. In order to facilitate the selection of specific preference function, six basic types of this preference function are proposed to decision maker by Brans and Vincke (1985) (usual function, U-shape function, V-shape function, level function, linear function and Gaussian function) in each case no more than two parameters (threshold, $q, p$ or $s$ ) have to fix (Brans and Mareschall 1994; Wang and Yang 2007). Indifference threshold $q$ : the largest deviation to consider as negligible on that criterion. It is a small value with respect to the scale of measurement. Preference threshold $p$ : the smallest deviation to consider decisive in the preference of one alternative over another. It is a large value with respect to the scale of measurement. Gaussian threshold $s$ : it is only used with the Gaussian preference function. It is usually fixed as an intermediate value between indifference and a preference threshold. PROMETHEE permits the computation of the following quantities for each alternative $a$ and $b$ : 
$\pi(a, b)=\frac{\sum_{j=1}^{n} \omega_{j} P_{j}(a, b)}{\sum_{j=1}^{n} \omega_{j}}$

$\Phi^{+}(a)=\sum_{x \in A} \pi(x, a)$

$\Phi^{-}(a)=\sum_{x \in A} \pi(a, x)$

$\Phi(a)=\Phi^{+}(a)-\Phi^{-}(a)$

For each alternative $a$, belonging to the set $A$ of alternatives, $\pi(a, b)$ is an overall preference index of $a$ over $b$. The leaving flow $\varphi^{+}(a)$ is the measure of the outranking character of $a$ (how $a$ dominates all the other alternatives of $A$ ). Symmetrically, the entering flow $\varphi^{-}(a)$ gives the outranked character of $a$ (how $a$ is dominated by all the other alternatives of $A$ ). $\varphi(a)$ represents a value function, whereby a higher value reflects a higher attractiveness of alternative $a$ and is called net flow. The two main PROMETHEE tools can be used to analyze the evaluation problem: (1) the PROMETHEE I partial ranking, (2) the PROMETHEE II complete ranking. The PROMETHEE I partial ranking provides a ranking of alternatives. In PROMETHEE I, alternative $a$ is preferred to alternative $b, a P b$, if alternative $a$ has a greater leaving flow than that of alternative $b$ and $a$ smaller entering flow than the entering flow of alternative $b$ :

$a P b$ if: $\Phi^{+}(\mathrm{a})>\Phi^{+}(\mathrm{b})$ and $\Phi^{-}(\mathrm{a})<\Phi^{-}(\mathrm{b})$; or

$$
\begin{aligned}
& \Phi^{+}(\mathrm{a})>\Phi^{+}(\mathrm{b}) \text { and } \Phi^{-}(\mathrm{a})=\Phi^{-}(\mathrm{b}) \text {; or } \\
& \Phi^{+}(\mathrm{a})=\Phi^{+}(\mathrm{b}) \text { and } \Phi^{-}(\mathrm{a})<\Phi^{-}(\mathrm{b})
\end{aligned}
$$

PROMETHEE I evaluation allows indifference and incomparability situations. Therefore, sometimes partial rankings can be obtained. In the indifference situation $(a I b)$, two alternatives $a$ and $b$ has the same leaving and entering flows:

aIb if: $\Phi^{+}(\mathrm{a})=\Phi^{+}(\mathrm{b})$ and

$\Phi^{-}(\mathrm{a})=\Phi^{-}(\mathrm{b})$

Two alternatives are considered incomparable, $a R b$, if alternative $a$ is better than alternative $b$ in terms of leaving flow, while the entering flows indicate the reverse:

$a R b$ if: $\Phi^{+}(\mathrm{a})>\Phi^{+}(\mathrm{b})$ and $\Phi^{-}(\mathrm{a})>\Phi^{-}(\mathrm{b})$; or

$$
\Phi^{+}(\mathrm{a})<\Phi^{+}(\mathrm{b}) \text { and } \Phi^{-}(\mathrm{a})<\Phi^{-}(\mathrm{b})
$$


PROMETHEE II provides a complete ranking of the alternatives from the best to the worst one. Here, the net flow $(\varphi)$ is used to rank the alternatives. The alternative with the higher net flow is assumed to be superior. Since PROMETHEE I does not provide a complete ranking, resulting ranking can not be compared with the ranking provided by PROMETHEE II. PROMETHEE I ensure creation of indifferent and incomparable alternatives. In some ranking problems, PROMETHEE I can give a complete ranking depending on the evaluation matrix values and, this ranking can not be different from the one achieved with PROMETHEE II.

\section{Numerical Example}

The large number of criteria that should typically be considered in selecting the best supplier, Using the structure of the six criteria $\mathrm{s}$ as the base and synthesizing the other literature, in current study dimension including Capacity $\left(\mathrm{C}_{1}\right)$, Delivery $\left(\mathrm{C}_{2}\right)$, Quality $\left(\mathrm{C}_{3}\right)$, Shipment Accuracy $\left(\mathrm{C}_{4}\right)$, Warranty Policies $\left(\mathrm{C}_{5}\right)$ and Availability of Raw materials $\left(\mathrm{C}_{6}\right)$. First of all we form the decision matrix, after that we compute $h_{i}, d_{i}$ and $w_{i}$ base on Shannon method that are shown in Table 1.

Table $1 . \mathrm{h}_{\mathrm{i}}, \mathrm{d}_{\mathrm{i}}$ and $\mathrm{w}_{\mathrm{i}}$ for each criteria

\begin{tabular}{|c|c|c|c|c|c|c|}
\hline Criteria & $\mathrm{C}_{1}$ & $\mathrm{C}_{2}$ & $\mathrm{C}_{3}$ & $\mathrm{C}_{4}$ & $\mathrm{C}_{5}$ & $\mathrm{C}_{6}$ \\
\hline $\mathrm{E}_{\mathrm{j}}$ & 0.978 & 0.983 & 0.977 & 0.888 & 0.983 & 0.917 \\
\hline $\mathrm{D}_{\mathrm{j}}$ & 0.022 & 0.017 & 0.023 & 0.112 & 0.017 & 0.083 \\
\hline $\mathrm{w}_{\mathrm{j}}$ & 0.079 & 0.062 & 0.085 & 0.409 & 0.062 & 0.304 \\
\hline
\end{tabular}

In PROMETHEE, firstly alternative are evaluated based on the evaluation criteria and the evaluation matrix is formed. The evaluations of these five alternatives according to the previously stated criteria, i.e., evaluation matrix, are displayed in Table 2.

Table 2. Evaluation matrix

\begin{tabular}{|c|c|c|c|c|c|c|}
\hline Alternative & $\mathrm{C}_{1}$ & $\mathrm{C}_{2}$ & $\mathrm{C}_{3}$ & $\mathrm{C}_{4}$ & $\mathrm{C}_{5}$ & $\mathrm{C}_{6}$ \\
\hline Weights & 0.07 & 0.062 & 0.085 & 0.409 & 0.062 & 0.304 \\
\hline $\mathrm{A}_{1}$ & 3 & 4.1 & 2.23 & 1.63 & 4.1 & 1 \\
\hline $\mathrm{A}_{2}$ & 2.5 & 3.1 & 3 & 2 & 3.1 & 6 \\
\hline $\mathrm{A}_{3}$ & 4 & 2.4 & 4.1 & 5 & 2.4 & 4 \\
\hline $\mathrm{A}_{4}$ & 2.5 & 2.8 & 2.5 & 1.24 & 2.8 & 5 \\
\hline $\mathrm{A}_{5}$ & 1.7 & 2.1 & 1.89 & 1.1 & 2.1 & 2.4 \\
\hline
\end{tabular}

Before using the PROMETHEE method to rank the alternative, for each criterion, a specific preference function (PF), with its thresholds is defined. Preference functions and threshold values have been defined by the decision-making team but in this paper, preference function $(\mathrm{PF})$, with its thresholds is defined by software. After evaluation matrix and preference functions are determined, alternatives are evaluated by using Decision Lab software. The positive flow $\left(\varphi^{+}\right)$, negative flow $\left(\varphi^{-}\right)$and net flow $(\varphi)$ values obtained from this evaluation are given in Table 3 . 
Table 3. PROMETHEE flows

\begin{tabular}{|c|c|c|c|}
\hline Alternatives & $\varphi^{+}$ & $\varphi-$ & $\varphi$ \\
\hline $\mathrm{A}_{1}$ & 0.4086 & 0.5914 & -0.1828 \\
\hline $\mathrm{A}_{2}$ & 0.7865 & 0.1938 & 0.5927 \\
\hline $\mathrm{A}_{3}$ & 0.7552 & 0.2448 & 0.5105 \\
\hline $\mathrm{A}_{4}$ & 0.4540 & 0.5262 & -0.0722 \\
\hline $\mathrm{A}_{5}$ & 0.0759 & 0.9241 & -0.8482 \\
\hline
\end{tabular}

By using the flow values in Table 3, firstly the partial ranking is determined via PROMETHEE I (Fig. 1). PROMETHEE I used positive and negative flow values to find the partial ranking. $A_{2}$ is determined as the best alternative according to the PROMETHEE I partial ranking and alternatives ranked as follow: $A_{2}, A_{3}, A_{4}, A_{1}$ and $A_{5}$. In this paper, the results of PROMETHEE II complete ranking are the same with PROMETHEE I partial ranking (Fig. 2).

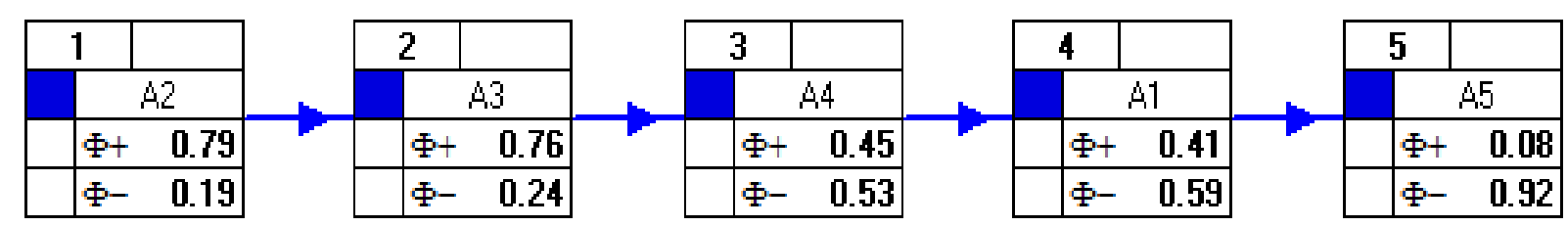

Figure 1. PROMETHEE I partial ranking

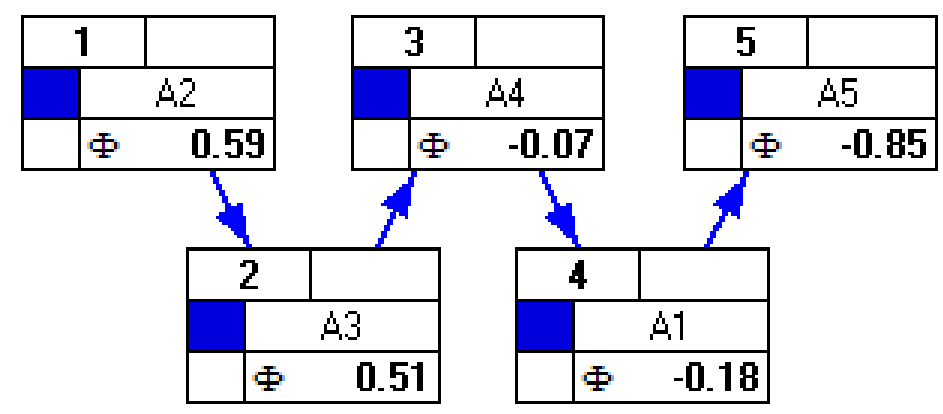

Figure 2. PROMETHEE II complete ranking

The decision problem can be represented in the GAIA plane (see Fig. 3) where alternative are represented by points and criteria by vectors. In this way, conflicting criteria may appear clearly. Criteria vectors expressing similar preferences on the data are oriented in the same direction, while conflicting criteria are pointing in opposite directions. The length of each vector is a measure of its power in alternative machines differentiation. This plane is the result of principal component analysis (PCA), projecting the 5-dimensional space of criteria onto a two-dimensional plane, i.e., the 5 original variables are transformed to the two new variables that are obtained by two linear combinations of the original variables. By applying the PCA related criteria are handled by these combinations and double counting never occurs (Albadvi et al. 2007). 


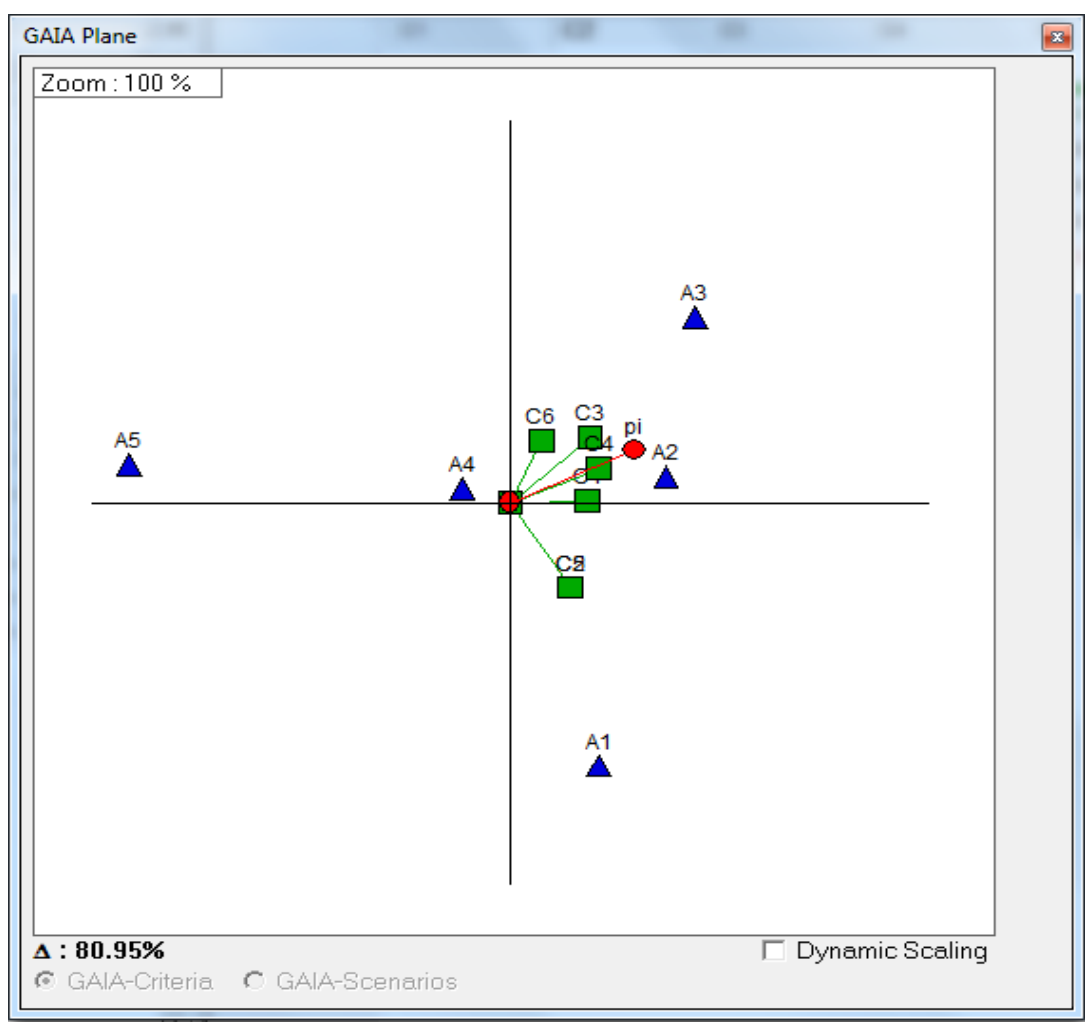

Figure 3. GAIA plane for supplier selection

According to the Shannon and PROMETHEE computations, $\mathrm{A}_{2}$ is the best alternative. How the variation in the criteria weights after the decision will affect the ranking is analyzed. Sensitivity analysis has been performed with Decision Lab Software and the resulting "stability intervals" values are given in Table 4 . Table 4 gives for each criterion the limits within weights' values which can vary without changing the PROMETHEE II complete ranking.

Table 4. Stability intervals

\begin{tabular}{|c|c|c|c|}
\hline \multirow{2}{*}{ Criteria } & \multirow{2}{*}{ Weight } & \multicolumn{2}{|c|}{ Interval } \\
\cline { 3 - 4 } & & Min & Max \\
\hline $\mathrm{C}_{1}$ & 0.079 & 0.0000 & 0.1448 \\
\hline $\mathrm{C}_{2}$ & 0.062 & 0.0000 & 0.1728 \\
\hline $\mathrm{C}_{3}$ & 0.085 & 0.0000 & 0.2495 \\
\hline $\mathrm{C}_{4}$ & 0.049 & 0.0202 & 0.5735 \\
\hline $\mathrm{C}_{5}$ & 0.062 & 0.0000 & 0.1728 \\
\hline $\mathrm{C}_{6}$ & 0.304 & 0.2302 & 1.4705 \\
\hline
\end{tabular}

\section{Conclusion}

Supplier selection is a broad comparison of suppliers using a common set of criteria and measures to identify suppliers with the highest potential for meeting a firm's needs consistently and at an acceptable cost. Selecting the right suppliers significantly reduces the 
purchasing costs and improves corporate competitiveness therefore supplier selection one of the most important decision making problems. In this paper, a two-step Shannon's Entropy and PROMETHEE methodology is structured here that PROMETHEE uses Shannon's Entropy result weights as input weights. According to this methodology, supplier 2 (A2) is selected as the best supplier. As a future direction, other decision-making methods such as fuzzy ELECTRE, Fuzzy Preference programming (FPP) and Fuzzy GTMA can be used in this area.

\section{References}

Albadvi, A., Chaharsooghi, S. K., \& Esfahanipour, A. (2007). Decision making in stock trading: An application of ROMETHEE. European Journal of Operational Research, 177, 673-683. http://dx.doi.org/10.1016/j.ejor.2005.11.022

Brans, J. P., \& Mareschall, B. (1994). The PROMCALC\&GAIA decision support system for multi-criteria decision aid. Decision Support Systems, 12, 297-310. http://dx.doi.org/10.1016/0167-9236(94)90048-5

Brans, J. P., \& Vincke, P. H. (1985). A preference ranking organization method. Management Science, 31, 647-656. http://dx.doi.org/10.1287/mnsc.31.6.647

Brans, J. P., Vincke, P. H., \& Mareschall, B. (1986). How to select and how to rank projects: The PROMETHEE method. European Journal of Operational Research, 14, 228-238. http://dx.doi.org/10.1016/0377-2217(86)90044-5

Cebi, F. and D. Bayraktar, (2003). An integrated approach for supplier selection. Logistics Information Management, 16(6), 395-400. http://dx.doi.org/10.1108/09576050310503376

Ellram, L. M, 1990. The supplier selection decision in strategic partnerships. Journal of Purchasing and Materials Management, 26(4), 8-14.

Ghodsypour, S. H. and O'Brien, C. (1998). A decision support system for supplier selection using an integrated analytic hierarchy process and linear programming. International Journal of Production Economics, 56(57), 199-212. http://dx.doi.org/10.1016/S0925-5273(97)00009-1

Jiang, Z. F., T. Y. Zhuang, and S. X. Lin, (2006). Empirical analysis of the effects of supplier selection and integration on customer satisfaction and business performance. In IEEE International Conference on management of innovation and technology (pp. 931-935).

Mergias, I., Moustakas, K., Papadopoulos, A., \& Loizidou, M. (2007). Multi-criteria decision aid approach for the selection of the best compromise management scheme for ELVs: The case of Cyprus. Journal of Hazardous Materials, 147, 706-717. http://dx.doi.org/10.1016/j.jhazmat.2007.01.071

Nijkamp, P., Rietveld, P., \& Voogd, H. (1990). Multicriteria evaluation in physical planning. Amsterdam: Elsevier Science Publishers.

Shemshadi, A., J. Soroor, and M. J. Tarokh, (2008). Implementing a multi-agent system for 


\section{Macrothink}

the real-time coordination of a typical supply chain based on the JADE Technology. In 3rd IEEE SMC international conference on system of systems engineering (pp. 1-6).

Soroor, J., M. J. Tarokh, and A. Shemshadi, (2009). Initiating a state of art system for real-time supply 196(2), chain coordination. European Journal of Operational Research, 635-650. http://dx.doi.org/10.1016/j.ejor.2008.03.008

Timmerman, E. 1986. An approach to vendor performance evaluation. Journal of Purchasing and Materials Management, 22(4), 2-9.

Wang, G., S. H. Huang, and J. P. Dismukes. (2004). Product-driven supply chain selection using integrated multi-criteria decision-making methodology. International Journal of Production Economics, 91, 1-15. http://dx.doi.org/10.1016/S0925-5273(03)00221-4

Wang, J. J., \& Yang, D. L. (2007). Using a hybrid multi-criteria decision aid method for information systems outsourcing. Computers \& Operation Research, 34, 3691-3700. http://dx.doi.org/10.1016/j.cor.2006.01.017

Wang, T.Y. and Y. H. Yang. (2009). A fuzzy model for supplier selection in quantity discount environments. Expert Systems with Applications, 36(10), 12179-12187. http://dx.doi.org/10.1016/j.eswa.2009.03.018

Weber, C. A. and J. R. Current, 1993. A multi objective approach to vendor selection. European Journal of Operational Research, 68, 173-184. http://dx.doi.org/10.1016/0377-2217(93)90301-3 